Cuadernos de Historia Contemporánea

ISSN: 0214-400X

http://dx.doi.org/10.5209/CHCO.60319

\title{
Dosier: Políticas y discursos sobre eugenesia y sexualidad en el siglo XX
}

Jean-Louis Guereña; ${ }^{1}$ Rafael Huertas García-Alejo ${ }^{2}$

Hace veinte años veía la luz un renovador y muy sugerente ensayo de Francisco Vázquez y Andrés Moreno Mengíbar que, con el título Sexo y Razón, se convirtió en una obra pionera y de referencia indiscutible para el gran número de estudios que sobre historia de la sexualidad en España han ido apareciendo en las últimas décadas. La notable impronta foucaultiana de este trabajo, y de otros muchos que siguieron su estela, ha convivido con otro tipo de acercamientos en un complejo entramado de enfoques y tendencias historiográficas, como la historia de la medicina, la historia social y cultural y, de manera particular, los llamados estudios culturales con sus múltiples vertientes: Gender Studies, Body Studies, Queer Studies, etcétera.

El amplio abanico de temáticas relacionadas con la sexualidad en tanto que práctica social y cultural, ha facilitado una serie muy rica de aportaciones de procedencias académicas muy diversas. Antecedentes importantes de este tipo de estudios son los dedicados a la historia de la prostitución, o de las "enfermedades venéreas" como se decía entonces, a la lectura que la ciencia positivista realizó de las llamadas "perversiones" o "desviaciones" sexuales. De manera particular, y especialmente fructífera, destacan las aportaciones a la historia de la eugenesia, una ciencia en la que se aunaba sexualidad, genética, higiene (racial y mental), pero también gobierno de las poblaciones, y en definitiva (bio)política. Sin embargo, en los últimos años han ido apareciendo trabajos que intentan una visión más interdisciplinar de la historia de la sexualidad. El número monográfico de la revista Hispania sobre "La sexualidad en la España contemporánea (1800-1950)" publicado en 2004 (http://hispania.revistas. csic.es/index.php/hispania/issue/view/17), supuso un punto de inflexión en este sentido, al que han seguido otros trabajos con similar vocación transversal.

En esta misma dinámica, el 25 de septiembre de 2014 se celebró en la Casa de Velázquez de Madrid una jornada con el título "La historia de la sexualidad en la época contemporánea", en la que se debatió sobre aspectos metodológicos y se presentaron estudios de caso que fueron objeto de una reflexión conjunta en un intento de actualizar temas y tendencias. Dicha jornada fue el germen del dossier que ahora se presenta pero el resultado final no es, ni mucho menos, la traslación de las ponencias que allí se presentaron. Conserva, eso sí, el empeño de repensar viejos temas (como la eugenesia o la reforma sexual) y de identificar aspectos que han ido aflorando en investigaciones recientes (los usos del psicoanálisis, masculinidad

1 Université François Rabelais (Université de Tours)

e-mail: jean-louis.guerena@univ-tours.fr

2 Consejo Superior de Investigaciones Científicas. Centro de Ciencias Humanas y Sociales (Madrid)

e-mail: rafael.huertas@cchs.csic.es 
y sexualidad masculina, etcétera) y que nos obligan a plantear nuevas preguntas y a transitar por nuevos derroteros. Nuevos caminos que tienen que ver también con un desplazamiento hacia épocas más recientes que incluyen la época franquista en España o contextos especialmente significativos, como es la Argentina de los años centrales del siglo XX.

Con tales objetivos, el presente dossier reúne a un grupo de especialistas que, con el denominador común de historia cultural y en busca de un horizonte comparado, abordan diversos aspectos de las políticas y los discursos sobre la eugenesia y la sexualidad en el siglo XX. Nerea Aresti, coeditora con Darina Martykánová del dossier publicado en el número anterior de estos mismos Cuadernos de Historia Contemporánea sobre "Masculinidades, nación y civilización en la España contemporánea", profundiza en esta ocasión en determinados aspectos de la sexualidad masculina en relación con el orden social en la España de entreguerras. Una masculinidad que es también el objeto del trabajo de Gustavo Vallejo, esta vez centrando el análisis en sus representaciones culturales en un contexto diferente al español, la Argentina del siglo XX.

Las relaciones entre sexualidad y eugenesia están presentes en otros dos trabajos del dossier, el de Ricardo Campos y el de Marisa Miranda. En contextos diferentes -de nuevo España y Argentina- ambos autores centran su análisis en las relaciones entre matrimonio, sexualidad y moral, y tratan de ver de qué manera éstas contribuyeron, desde posiciones conservadoras, a construir categorías como la de "esposa" o la de "madre ideal" en el marco de un discurso eugénico de signo autoritario.

El dossier se completa con la aportación de Silvia Lévy y Rafael Huertas sobre la utilización del psicoanálisis en el debate en torno a la llamada Reforma Sexual española de los años veinte y treinta, y se cierra con una reflexión en primera persona de Francisco Vázquez sobre su propia obra Sexo y Razón, citada al comienzo de esta introducción, publicada ahora ya hace casi veinte años y desde entonces un referente indiscutible de este tipo de estudios en España. Un trabajo que permitirá al lector apreciar el valor de un clásico de nuestra historiografía, identificar algunos de los caminos que fue abriendo y valorar la evolución intelectual de su autor en el ámbito cada vez más amplio de los estudios culturales sobre sexualidad. 